\title{
Physiology of the Cell Surface of Neurospora Ascospores. II. Interference with Dye Adsorption by Polymyxin
}

\author{
Robert J. Lowry and Alfred S. Sussman \\ From the Department of Botany, University of Michigan, \\ Ann Arbor, Michigan ${ }^{1}$
}

Received October 3, 1955

\section{INTRODUCTION}

One reason frequently advanced to explain the toxic effect of antibiotics is their effect upon the cell surface and the consequent disruption of cellular permeability. That this explanation may hold for the toxicity of the polypeptide polymyxin is suggested by the work of Newton $(9,10)$ and of Few and Schulman (3) who have shown that this substance combines with the cell wall of certain bacteria. Contributing to the evidence that this antibiotic affects the cell surface are the data of Sussman and Lowry (14) which demonstrate that the adsorption of methylene blue by ascospores of Neurospora is precluded by treatment with polymyxin. It was the purpose of the following experiments to study this phenomenon in more detail and to determine the effect of this substance upon fungal spores.

\section{Materials and Methods}

Ascospores of Neurospora tetrasperma have been used in these experiments because of the convenience with which they can be manipulated and the ease with which the metabolic states of the organism can be controlled. The stable and relatively low respiratory rate characteristic of the dormant cells may be interrupted at any time by the application of heat or chemicals. This results in a drastic change in the metabolism of the organism signalized by a 15 - to 20 -fold increase in gas exchange and by other differences (6).

Strains 374 and 377 of $N$. tetrasperma were crossed and grown at $25^{\circ} \mathrm{C}$. for about 28 days before the ascospores were harvested according to the methods outlined by Goddard (5).

1 This work was aided by funds furnished by the Rackham Fund of the University of Michigan. Paper No. 11 from the Plant Nutrition Laboratory, Michigan Memorial Phoenix Project No. 32, of the University of Michigan. 
Cell fragments were prepared by two means, including treatment with sulfuric acid, and by grinding. In the first method, equal parts of a cell suspension and of conc. sulfuric acid were mixed in an ice bath, and the mixture was incubated in a shaking machine for $24 \mathrm{hr}$. at $25^{\circ} \mathrm{C}$. At this time the ascospores were washed free of the acid by centrifugation in distilled water until the supernatant was no longer cloudy. The second method utilized a homogenizer of the Potter-Elvehjem type for fragmenting the ascospores. These were ground for $10 \mathrm{~min}$. and washed in ten changes of distilled water followed by ten changes of $0.5 \% \mathrm{NaCl}$. Before use, both sets of spores were resuspended in distilled water and diluted to the desired concentration.

Quantitative determinations of polymyxin were carried out by the method of Cocking and Yemm (1) wherein Methyl Cellosolve was used in order to raise the boiling point of the ninhydrin solution. The only modification of their procedure was the addition of $10 \mathrm{ml}$. of $60 \%$ ethyl alcohol to the samples before readings were made in the Evelyn colorimeter with a $565 \mathrm{~m} \mu$ filter. Under these conditions a sensitivity of at least $0.1 \mu \mathrm{g} . / \mathrm{ml}$. was achieved.

\section{Results}

\section{Effect of Polymyxin Treatment upon Germination}

The toxicity of polymyxin for ascospores was studied by adding various concentrations of the antibiotic to an equal volume of a suspension containing $0.5 \mathrm{mg}$. ascospores $/ \mathrm{ml}$. Activation of these spores had previously been effected by maintaining them at a temperature of $60^{\circ} \mathrm{C}$. for $15 \mathrm{~min}$. These mixtures were then incubated on a shaking machine for $3 \mathrm{hr}$. at $30^{\circ} \mathrm{C}$., after which the spores were killed by adding a few drops of formalin. The percentage germination was then determined. The results disclosed that the $M L D_{50}$ of polymyxin for ascospores is between 3 and 4 p.p.m.

There is evidence that cations are able to reverse the toxic effect of polymyxin toward bacteria (9). Therefore, a spore suspension was prepared and activated as described previously, and $0.5 \mathrm{ml}$. of various salt solutions, $0.5 \mathrm{ml}$. of a solution containing 50 p.p.m. polymyxin, and 1.0 $\mathrm{ml}$. of the spore suspension were mixed, incubated, and counted as above. These results showed that calcium and magnesium $\left(2.5 \times 10^{-2} M\right)$ reversed the toxic effect of the antibiotic, although not completely.

The effect of polymyxin upon the respiratory metabolism of Neurospora was then studied by means of the usual manometric techniques (15). In order to obtain measurable respiratory rates, rather dense cell suspensions had to be used, so that correspondingly higher amounts of polymyxin were required. Therefore, each Warburg vessel (total volume ca. $7 \mathrm{ml}$.) contained $5.8 \mathrm{mg}$. of ascospores per vessel in a fluid volume of 


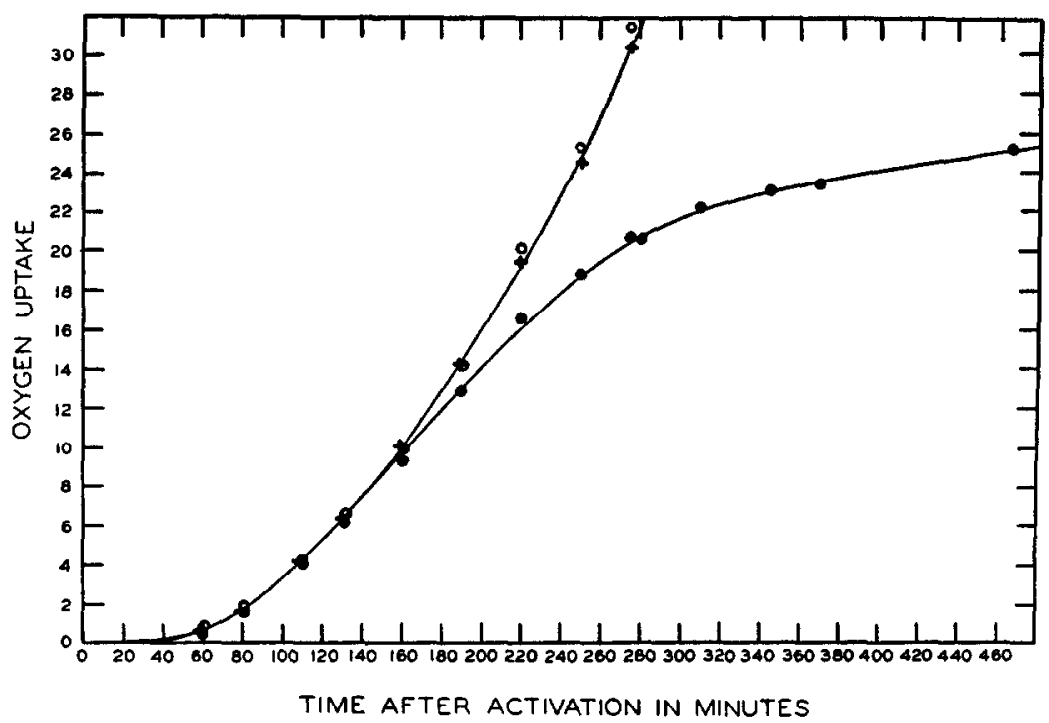

FIg. 1. Effect of polymyxin upon the respiration of activated ascospores of $N$. tetrasperma. Legend: closed circles, 500 p.p.m. polymyxin (no germination); plus marks, 500 p.p.m. polymyxin $+0.1 M \mathrm{Ca}^{++}(93 \%$ germination); open circles, untreated control ( $90 \%$ germination). Each vessel contained: $0.4 \mathrm{ml}$. ascospore suspension containing $5.8 \mathrm{mg}$.; $0.5 \mathrm{ml}$. polymyxin, 1000 p.p.m.; or $0.5 \mathrm{ml}$. distilled water. The fluid volume was made up to $1.0 \mathrm{ml}$. with water or with $0.1 \mathrm{ml}$. of 1 $M \mathrm{CaCl}_{2}$.

$1.0 \mathrm{ml}$. A polymyxin solution, or distilled water, was tipped at zero time, and measurements were made at $26^{\circ} \mathrm{C} . \mathrm{CaCl}_{2}$ (final concentration $0.1 \mathrm{M}$ ) was added in some cases in order to reverse the toxic effect of polymyxin. As Fig. 1 shows, the effect of the antibiotic upon the organism's respiration does not become manifest until $2 \mathrm{hr}$. after the ascospores had been activated. Until that time the oxygen uptake of both control and treated cells is parallel, but beyond $120 \mathrm{~min}$. the respiration of the latter rapidly diminishes. As in the previous experiments, $\mathrm{Ca}^{++}$effectively reversed the toxicity of the antibiotic both as far as its effect upon respiration and germination is concerned.

It was evident from the preceding data that a change in the physiology of the activated ascospore occurs about $120 \mathrm{~min}$. after activation. Such a change could be due to the inability of the ascospores to absorb polymyxin until that time. To test this possibility, the uptake of polymyxin by dormant and activated ascospores was studied. This was accomplished 


\section{TABLE I}

Uptake of Polymyxin by Dormant and Activated Ascospores of $\mathbf{N}$. tetraspermi Activation was accomplished by heating at $60^{\circ}$ for $15 \mathrm{~min}$. Starting concentration of polymyxin was $10 \mu \mathrm{g} . / \mathrm{ml}$., and of cells was $1 \mathrm{mg} . / \mathrm{ml}$.

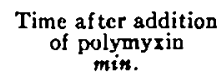

5

30

60

90

120

$3 \mathrm{hr}$.

$8 \mathrm{hr}$.

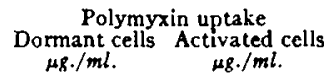

1.4

1.9

1.7

$-$

1.8

1. 7

2.2
1.4

1.8

1.8

1.8

0.4

$+0.3^{n}$

$+0.5^{n}$

- An increase in ninhydrin-positive material, compared with the starting level, occurred at this time.

by mixing equal volumes of cell suspensions and polymyxin such that the final concentrations were $1 \mathrm{mg} . / \mathrm{ml}$. and $10 \mu \mathrm{g} . / \mathrm{ml}$., respectively. The mixtures were incubated by shaking at $25^{\circ} \mathrm{C}$., during the course of which 2-ml. aliquots were withdrawn at various times after the start of incubation. One-milliliter samples of these were used in the determination of residual polymyxin after removal of the spores by centrifugation. As is indicated by the data in Table $I$, dormant and activated cells remove approximately equivalent amounts of polymyxin from solutions almost immediately upon being exposed to the antibiotic. However, after $90 \mathrm{~min}$. the apparent uptake of activated cells is markedly diminished while that of dormant ones rises somewhat. The nonspecific nature of the ninhydrin analysis of polymyxin renders difficult the interpretation of these data, which will be discussed in more detail later. What is clear, however, is the different responses of the dormant and activated cells to polymyxin after about $120 \mathrm{~min}$. of exposure.

\section{Localization of Polymyxin}

Cationic dyes such as methylene blue have been shown by a variety of means to be adsorbed in the surface of the Neurospora ascospore (14). Although many cations act to delay such adsorption for a short time if they are added before the dye, few can prevent dye uptake beyond an hour. Among those that do are polymyxin $B$ sulfate, which can markedly reduce the amount of methylene blue taken up for longer than $24 \mathrm{hr}$. It seemed likely, therefore, that the antibiotic could be acting by virtue of its localization on the surface of the cell. 
This hypothesis was based upon the notion that the polymyxin-binding sites must be close to, or identical with, the sites which adsorb the dye. Such spatial proximity would then account for the observed effect of the antibiotic. This possibility was investigated making use of the Hofstee (8) modification of the Michaelis-Menten equation according to which:

$$
v=V_{\max }-K_{m}(v /[s])
$$

where $\quad v=$ velocity of the reaction

$V_{\max }=$ maximum velocity attainable in this system

$[s]=$ substrate concentration

$K_{m}=$ Michaelis constant

In its most general sense this relationship describes the combination of any two entities with affinity for one another, so that it should be applicable to adsorption phenomena. This is, of course, subject to whether the system meets the basic assumptions necessary in the expansion of this equation $(4,11)$. Consequently, a plot of $v / S$ against $v$ should provide a straight line if the data conform to the original assumptions. Moreover, the intercept on the $y$ axis should be $V_{\max }$ while the slope equals $K_{m}$.

In order to apply these ideas to the problem of dye uptake by cells, several methylene blue concentrations were made up in $0.02 M$ phosphate buffer, $\mathrm{pH}$ 7.9. To an equal volume of the dye solutions was added $6.0 \mathrm{ml}$. of a suspension of ascospores $(1 \mathrm{mg} . / \mathrm{ml}$.), and the mixture was immediately incubated on a shaking machine at $25^{\circ} \mathrm{C}$. After $10 \mathrm{~min}$. exposure to the dye, the cells were removed by centrifugation and the residual dye concentration was determined by the use of an Evclyn colorimeter and a $660 \mathrm{~m} \mu$ filter. These data are provided in Fig. 2. Furthermore, the $K_{m}$ and $V_{\max }$ values were calculated by the method of least squares, and are presented in Table II. As can be seen by these data, a straight line is obtained when the data are plotted according to Eq. (1), suggesting that, in the concentration range used, at least, the assumptions on which the Michaelis-Menten analysis is based are met by this system.

It was now possible to study the competition between methylene blue and polymyxin for the cell surface by the simultaneous addition of these substances to a cell suspension. This was accomplished by mixing $3.0 \mathrm{ml}$. 


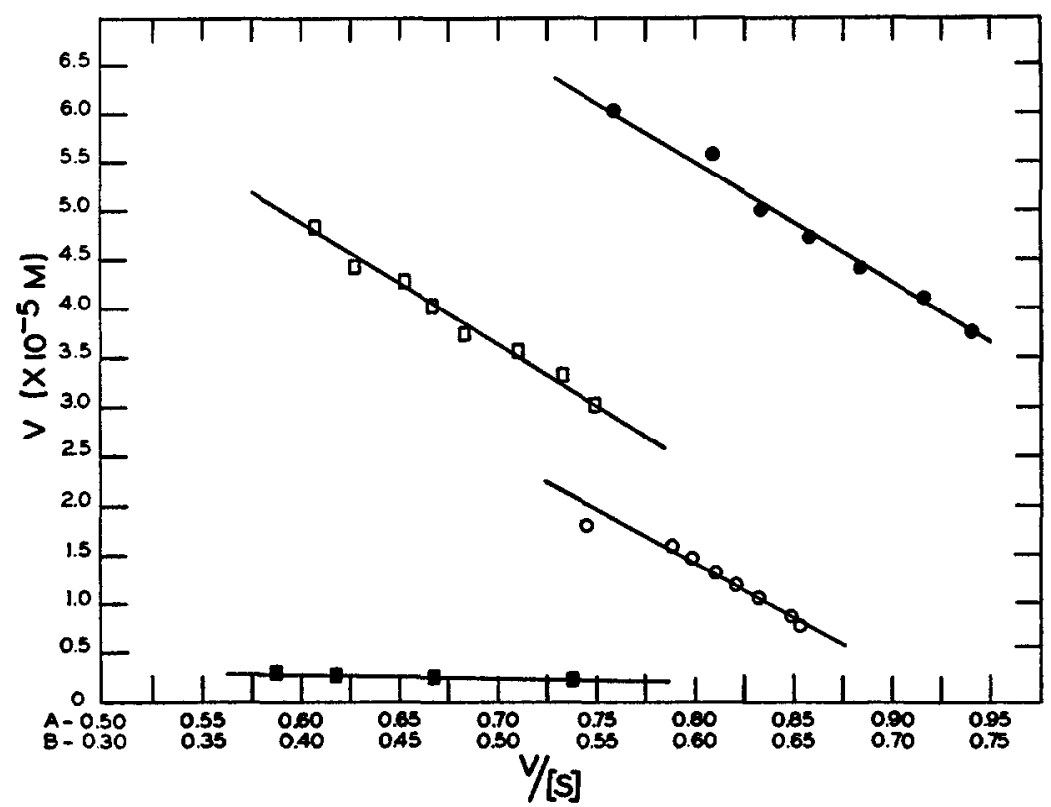

FIG. 2. Hofstce plots of methylene blue (MB) uptake in the presence of polymyxin. Legend: closed circles, uptake of methylene blue alone; open circles, uptake of MB in presence of 300 p.p.m. polymyxin; open squares, uptake of MB in presence of 30 p.p.m. polymyxin; closed squares, uptake of $\mathrm{MB}$ after pretreatment with polymyxin. All data are plotted with reference to the upper set of data on the abscissa (scale $A$ ) except for the pretreated cells which are plotted against the lower set (scale $B$ ).

\section{TABLE II}

Summary of Constants Computed from Data on Dye Adsorption in the Presence and Absence of Polymyxin

The method of least-squares was used in these calculations

\section{Treatment}

Simultaneous addition of polymyxin and methylene blue

Buffer control

30 p.p.m. polymyxin

300 p.p.m. polymyxin

$24 \mathrm{hr}$. incubation in polymyxin and subsequent removal of residual antibiotic before addition of the dye

12,000 p.p.m. polymyxin

$$
K_{m} \times 10^{-5} \mathrm{M} V_{\max }
$$

12.20

10.94 
of a solution containing 1200 p.p.m. polymyxin (approx. $0.001 \mathrm{M}$ ) and $3.0 \mathrm{ml}$. of various methylene blue solutions. This mixture was then added to an equal volume of a cell suspension, and the uptake of methylene blue was studied as described above. This experiment was performed with two concentrations of polymyxin giving final concentrations of 300 p.p.m. (approx. $2.5 \times 10^{-4} M$ ) and 30 p.p.m., and the results outlined in Fig. 2. The $K_{m}$ and $V_{\max }$ were calculated as before and listed in Table II. As can be seen from the data in Fig. 2 and Table II, the slopes of the controls and the polymyxin-treated cells are the same although the intercepts differ.

It has been noted by Sussman and Lowry (14) that preincubation of ascospores with polymyxin and subsequent treatment with methylene blue resulted in almost total exclusion of the dye from the cell surface for extended periods of time. Therefore, ascospores were incubated with $0.01 M$ polymyxin in $0.01 M$ phosphate buffer, at $\mathrm{pH} 7.9$, for $24 \mathrm{hr}$. on a shaking machine at $25^{\circ} \mathrm{C}$. The cells were then washed free of the antibiotic by several centrifugations in distilled water, after which they wcre made up to a density of $1 \mathrm{mg}$./ml. Methylene blue uptake was studied as before, and the results are provided in Fig. 2. It is at once apparent that pretreatment of cells with polymyxin is much more effective in preventing dye uptake than is simultaneous addition of dye and antibiotic. This is reflected as well in the values for the $K_{m}$ and $V_{\max }$ which are given in Table II. In contrast to the previous experiments wherein the antibiotic was added simultaneously with the dye, the slope of the curve describing dye uptake in this experiment was markedly different from that for the control. Pretreatment with amounts of polymyxin equivalent to those used in the previous experiments gave slopes that were intermediate between the controls and those obtained with $0.01 M$.

The analysis of the type of inhibition represented by the data in Table II and Fig. 2 was now possible by use of the classification of Ebersole, Guttentag, and Wilson (2). By this means it can be seen that the simultaneous addition of polymyxin and dye results in a noncompetitive (Type III) inhibition in contrast to the uncompetitive type (Type IV) represented by cells that are pretreated with the antibiotic. It should be noted that there is no direct reaction between polymyxin and methylene blue since the absorption spectrum of their mixture was identical to the sum of their individual absorptions over the range from 230 to $320 \mathrm{~m} \mu$.

A more direct approach to the localization of the polymyxin in the cell was possible by the use of cell fragments from which the cytoplasm 
had been removed. It had been demonstrated that such material, as well as killed cells, was able to remove methylene blue from solution almost as rapidly as did intact cells (14). Therefore, if it could be demonstrated that polymyxin was taken up by cell fragments, then its localization upon the cell surface could be considered likely.

With this in mind the cells were fragmented in the two ways described under Methods, namely, by digestion with sulfuric acid and by grinding and washing in water and in $\mathrm{NaCl}$. These cell fragments appear to be angular remnants of the cell wall and have retained much of the color of the original black spores. They were diluted in distilled water to approximately $1 \mathrm{mg} . / \mathrm{ml}$. (dry weight) and mixed with enough polymyxin, in $0.01 M$ phosphate buffer, $\mathrm{pH} 7.9$, to provide a final concentration of $1.2 \%$. The cell fragments were incubated in the polymyxin for $24 \mathrm{hr}$. at $25^{\circ} \mathrm{C}$. on a shaking machine, after which they were washed free of the antibiotic and made up to their original concentration. Methylene blue uptake was then studied as before, using a final concentration of $2 \times$ $10^{-5} M$ of the dye. The results are provided in Table III and indicate that polymyxin treatment has greatly delayed dye uptake by both types of cell fragments, although those prepared by sulfuric acid treatment were affected more.

If the contention that polymyxin is attached to the cell surface has

TABLE III

Methylene Blue Uptake by Fragments of Cells Obtained by Sulfuric Acid Treatment and by Grinding and Extraction in Water and $\mathrm{NaCl}$

Cell fragments were treated with polymyxin as described in text. Starting concentration of dye was $2 \times 10^{-5} \mathrm{M}$. Dashes indicate that no readings were made.

\begin{tabular}{|c|c|c|c|c|}
\hline \multirow{2}{*}{ Time after exposure to dye } & \multicolumn{2}{|c|}{ Controls } & \multicolumn{2}{|c|}{ Polymyxin treated } \\
\hline & Dyc uptake & $\begin{array}{c}\text { Per cent } \\
\text { dye uptake }\end{array}$ & Dye uptake & $\begin{array}{l}\text { Per cent } \\
\text { dye uptake }\end{array}$ \\
\hline & $\times 10^{-5} \mathrm{M}$ & & $\times 10^{-5} \mathrm{M}$ & \\
\hline \multicolumn{5}{|l|}{ Sulfuric acid fragments } \\
\hline $10 \mathrm{~min}$ & 1.92 & 96 & 0.52 & 26 \\
\hline $2 \mathrm{hr}$ & - & -- & 1.35 & 67 \\
\hline $6 \mathrm{hr}$. & - & 一 & 1.54 & 77 \\
\hline $30 \mathrm{hr}$. & - & - & 1.68 & 84 \\
\hline \multicolumn{5}{|l|}{ Ground fragments } \\
\hline $10 \mathrm{~min}$. & 1.95 & & 1.20 & 60 \\
\hline $1 \mathrm{hr}$. & - & & 1.68 & 85 \\
\hline $8 \mathrm{hr}$. & - & & 1.92 & 96 \\
\hline
\end{tabular}


TABLE IV

Uptake of Polymyxin by Cell Fragments as Described in the Section on Methods Starting concentration of polymyxin was $10 \mu \mathrm{g} . / \mathrm{ml}$.

$\begin{array}{ccc}\begin{array}{c}\text { Time after addition } \\ \text { of polymyxin }\end{array} & \begin{array}{c}\text { Sulfuric acid } \\ \text { treated } \\ \mu g . / m l .\end{array} & \begin{array}{c}\text { uptake } \\ \text { Ground } \\ \text { fragments }\end{array} \\ 5 \mathrm{~min} . / \mathrm{ml} . \\ 30 \mathrm{~min} . & 0.3 & - \\ 60 \mathrm{~min} . & - & 2.1 \\ 2 \mathrm{hr} . & 5.0 & 2.3 \\ 8 \mathrm{hr} . & - & 2.4 \\ 22 \mathrm{hr} . & 5.3 & 3.3 \\ 96 \mathrm{hr} . & 5.4 & 2.9 \\ & 5.5 & -\end{array}$

validity, then the cell fragments used above should remove the antibiotic from solution. On this basis, then, suspensions of cell fragments containing approximately $2 \mathrm{mg}$./ $/ \mathrm{ml}$. were added to an equal volume of a polymyxin solution containing $20 \mu \mathrm{g} . / \mathrm{ml}$. in distilled water and incubated by shaking at $25^{\circ}$. Aliquots were withdrawn at intervals and analyzed for residual polymyxin as described previously. The results, as provided in Table IV, show that over $3 \mu \mathrm{g} . / \mathrm{ml}$. of polymyxin is taken up in the case of the ground cell preparations, while over $5.0 \mu \mathrm{g}$. was removed by the sulfuric acid-treated material. An explanation of the larger amounts removed by the cell fragments as compared with whole cells (Table I) may lie in the smaller size of the fragments with the consequent increase in area per unit mass and in the inclusion in the dry weight of the whole cells of the intracellular contents.

\section{Discussion}

These experiments show that polymyxin B prevents the germination of ascospores of $N$. tetrasperma in low concentration. Hilborn (7) found that Rhizoctonia infection and Verticillium wilt of potato stems were considerably reduced by treatment with polymyxin, among other antibiotics. That the roots of higher plants are also susceptible to polymyxin inhibition has recently been reported by Norman (12). It is interesting to note that MLD for ascospores is approximately the same as for corn roots. Other compounds of this type, that is, highly charged peptides of fairly high molecular weight, are known to be good antibiotics, such as gramicidin and tyrocidin and synthetic poly- $\alpha$-amino acids of basic nature.

The mechanism of the action of polypeptides has often been attributed to their strongly basic groups which facilitate their approach to the nega- 
tively charged macromolecules on the cell surface and, perhaps, to certain enzymes. This possibility has been suggested as an explanation of the toxicity of polymyxin $\mathrm{E}$ to certain bacteria by Newton (10) and by Few and Schulman (3). They found that polymyxin treatment induced the leakage of cellular constituents which had an absorption maximum at $260 \mathrm{~m} \mu$ and rendered proteins of the cell susceptible to combination with fluorescing dyes (11). On these bases it was concluded that polymyxin was acting by virtue of its combination with the cell surface.

Such an explanation would also seem reasonable for the toxicity of polymyxin B to ascospores of Neurospora for the following reasons: (a) The kinetics of absorption resemble those of the usual Langmuir or Freundlich type, and a saturation level is rapidly achieved; $(b)$ cations compete with polymyxin for absorbing sites; (c) cationic dye absorption, which has been shown to take place on the cell surface (14), is largely precluded by polymyxin treatment; and $(d)$ cell fragments, free of cytoplasm, absorb polymyxin (Tables III and IV).

Some indication that the sites which bind methylene blue differ from those binding polymyxin is furnished by the data in Table II which are based upon the calculation of Michaelis-Menten constants. Competition for the same sites on the cell would have required that the intercepts $\left(V_{\max }\right)$ of the curves in Fig. 2 be the same, and that the effect of polymyxin treatment be reversed by excess of dye. Yet, in the cases studied, the intercepts were different, nor was reversal accomplished by increased concentrations of methylene blue. When dye and antibiotic were added simultaneously, the inhibition of dye uptake was of the noncompetitive type, since the slopes were almost equal, suggesting that the interfering cation, polymyxin, attaches to a reactive group that is different from that which binds methylene blue. This site, however, must be close enough to cause interference by the antibiotic with dye uptake. When the cells are pretreated with polymyxin, the slopes of the control and treated cells differ as well as do their intercepts, indicating an uncompetitive type of inhibition. In this case as well, the interference is not directly with the dye-binding sites themselves but with the dye-site complex or with adjacent sites not identical with those invoked for the case of noncompetitive inhibition. The nature of these sites must at present remain vague because of our limited knowledge of the structure of the cell surface.

Several lines of evidence show that the toxicity of polymyxin to ascospores of Neurospora does not become manifest until about $120 \mathrm{~min}$. 
after these cells are activated. The most direct evidence is that provided by the respiratory data in Fig. 1 which show that the oxygen uptake of activated cells remains unaffected until this time. These data are supported by the observation that after about $120 \mathrm{~min}$. ninhydrin-positive material is lost by activated cells. That a change occurs in the physiology of the ascospore after this time is demonstrated by previous data which showed that inhibition by ethylenediaminetetraacetic acid (EDTA) was freely reversible until $120 \mathrm{~min}$. after activation, but not beyond this time (13). In the case of EDTA, however, no measurable uptake could be detected, whereas polymyxin is absorbed. These data suggest, therefore, either that the antibiotic enters the interior of the cell at about 120 min. after activation or that it becomes toxic in situ because of an alteration in the cell surface which renders it susceptible to osmotic damage. The latter possibility is supported by the present data and by the fact that $\mathrm{K}^{+}$ions leak out of the cells in response to EDTA (13), but the alternative hypothesis cannot be discounted since a change in permeability might be merely a secondary effect of intracellular origin.

\section{ACKNOWLEDGMENTS}

The polymyxin $R$ sulfate $(71,000$ units/mg.) used in these experiments was obtained through the kindness of Dr. Louis G. Nickell of the laboratories of Pfizer \& Company, Brooklyn, New York. Also, the authors would like to acknowledge the cooperation of Professor A. G. Norman who made available the laboratory and equipment of the Plant Nutrition Laboratory, Phoenix Project No. 32 of the University of Michigan.

\section{SUMmary}

Polymyxin B prevents the germination of ascospores of Neurospora tetrasperma with an $L D_{60}$ of 3-4 p.p.m. The toxic effect of polymyxin is partially reversed by calcium and magnesium ions. The effect of polymyxin on the respiration of activated ascospores does not become apparent until after $2 \mathrm{hr}$. The effect upon respiration is reversed by calcium ions. Dormant and activated ascospores remove about the same amount of polymyxin from solution almost immediately upon exposure to the antibiotic. After $90 \mathrm{~min}$. the apparent uptake of activated cells is markedly diminished while that of the dormant spores increases slightly. Polymyxin competes noncompetitively with methylene blue for sites on the surface of the cells when added simultaneously with the dye. However, if the antibiotic is added before methylene blue, dye uptake is almost entirely suppressed and an uncompetitive type of inhibition 
results. These data, in conjunction with those showing polymyxin uptake by cell-wall fragments, suggest that the antibiotic occupies sites on the surface of the ascospore and that these sites differ from those binding methylene blue.

\section{REFERENCES}

1. Cocking, E. C., and Yemm, E. W., Biochem. J. 55, xii (1954).

2. Ebersole, E. R., Guttentag, C., and Wilson, P. W., Arch. Biochem. 3, 399 (1943).

3. Few, A. V., and Schulman, J. H., J. Gen. Microbiol. 9, 454 (1953).

4. Friedenwald, J. S., and Maengwyn-Davies, G. D., in "The Mechanisms of Enzyme Action" (McElroy, W. D., and Glass, B., eds.), p. 154. The Johns Hopkins Press, Baltimore,1954.

5. Goddard, D. R., J. Gen. Physiol. 19, 45 (1935).

6. Goddard, D. R., Cold Spring Harbor Symposia Quant. Biol. 7, 362 (1939).

7. Hilborn, M. T., Phytopathology 43, 475 (1953).

8. Hofstee, H. J., Science 116, 329 (1952).

9. Newton, B. A., J. Gen. Microbiol. 9,54 (1953).

10. Newton, B. A., J. Gen. Microbiol. 10, 491 (1954).

11. Nielands, J. B., and Stumpf, P. K., "Outlines of Enzyme Chemistry." John Wiley and Sons, Inc., New York, 1955.

12. Norman, A. G., Arch. Biochem. and Biophys. 58, 461 (1955).

13. Sussman, A. S., J. Gen. Physiol. 38, 59 (1954).

14. Sussman, A. S., and Lowry, R. J., J. Bacteriol. 70, 675 (1955).

15. Umbreit, W. W., Burris, R. H., And Stauffer, J. F., "Manometric Techniques and Tissue Metabolism." Burgess Publ. Co., Minneapolis, 1949. 